\title{
HOW TO MEET EMPLOYEES' EXPECTATIONS IN TERMS OF JOB SATISFACTION AND STABILISATION IN THE AGRIBUSINESS INDUSTRY
}

\author{
Nadežda Jankelová ${ }^{1}$, Zuzana Joniakován ${ }^{2}$ Katarina Remeňová ${ }^{3}$, Ildikó Némethová ${ }^{4}$ \\ *Corresponding author E-mail: nadezda.jankelova@euba.sk
}

A R T I C L E I N F O
Original Article
Received: 26 October 2020
Accepted: 23 August 2021
doi:10.5937/ekoPolj2103583J
UDC 331.108.22:631.145

Keywords:

$s$ agribusiness company,

human resources, motivation, satisfaction, stabilization

JEL: M12, P3,Q19

\begin{abstract}
A B S T R A C T
Motivation is one of the most important management tools to ensure employees' job satisfaction and stabilisation. Effective motivation programmes can only be developed through an in-depth understanding of employee motivation profiles. The aim of this paper is to analyse the motivation factors of employees in terms of their job satisfaction and stabilisation in the agribusiness industry. The methodological framework of the survey is Herzberg's two-factor motivation theory. Independent variables were tested using test statistic methods with the most significant deviations. An independent t-test was used for each motivation factor. The biggest negative deviations were found in the factors of income, responsibility and working conditions, employee benefits, content of work, its recognition and the possibility of advancement. A statistically significant difference was found at the age and education of respondents. Younger employees and university-educated employees showed a marked difference between their expectations and satisfaction by employers.
\end{abstract}

(C) 2021 EA. All rights reserved.

1 Nadežda Jankelová, professor,University of Economics in Bratislava, Faculty of Business Management, Bratislava, Slovak Republic, Phone: +421 2 67295643, E- mail: nadezda. jankelova@euba.sk, ORCID ID (https://orcid.org/0000-0002-0045-4737)

2 Zuzana Joniaková,associate professor,University of Economics in Bratislava, Faculty of Business Management, Bratislava, Slovak Republic, E - mail: zuzana.joniakova@euba.sk, ORCID ID (https://orcid.org/0000-0002-7706-2977).

3 Katarína Remeňová, assistant professor, University of Economics in Bratislava, Faculty of Business Management, Bratislava, Slovak Republic, E - mail: katarina.remenova@euba.

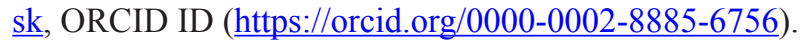

4 Ildikó Némethová,assistant professor, University of Economics in Bratislava, Faculty of Applied Languages, Bratislava, Slovak Republic, E - mail: ildiko.nemethova@euba.sk 


\section{Introduction}

Agribusiness has many functions in society in relation to long-term sustainability. It ensures the production of healthy, high-quality food, protects natural resources and the cultural landscape, while contributing to the maintenance of a viable rural area (Blaas et al., 2010). Its role in securing job opportunities is also irreplaceable. All these functions lead to the need to promote the sustainability of the agribusiness industry. An important role is played by the formation and stabilisation of employee potential in agribusiness, which is the task of management. Understanding the motivation profiles of employees can help agribusiness companies create conditions that contribute to job satisfaction and hence stabilise the human factor in the sector. Employee motivation is an important tool in business management and is closely related to other crucial tools such as remuneration and job satisfaction (Armstrong and Murlis, 2007). Knowledge of motivation profiles of employees is the starting point of creating motivation programmes leading to job satisfaction. Motivation theories help to clarify the nature of human behaviour and find ways to guide and support human initiative and action towards a particular goal. The most renowned theories include Alderfer's ERG theory, Herzberg two-factor theory, McClelland's achievement theory, Maslow's needs hierarchy theory, Adams equality theory, the expectation theory, the stimulus theory, and motivational work design. It should be, however, pointed out that neither of them provides guaranteed guidance for effective motivation. Similarly, it would not be appropriate to consider them as independent and prefer only some of them. They can complement each other to create an effective integrated whole as a theoretical basis for motivation processes in practice. An important fact is that the choice of appropriate motivation tools depends on the structure of employees' needs and their intensity. It is therefore clear that the basis of an effective motivation programme of any organisation is the knowledge of the motivation structure of individual employees or groups or professions and thorough considerations about the choice of motivation tools.

The basic motivation tool in a company is its remuneration system. A comprehensive holistic approach is applied to remuneration, in which the concept of total compensation resonates. This includes various types of rewards, such as indirect, direct, internal and external (Manas and Graham 2002). Total remuneration includes everything that employees perceive as fair compensation, in exchange for their effort and time spent at work (Chen and Hsieh 2006). Total remuneration is therefore a crucial tool for managing problems related to the recruitment and stabilisation of employees, as well as influencing their behaviour. Some authors refer to three main categories of remuneration that co-create total remuneration, i.e. external, internal and social (Williamson et al. 2009, Morgan et al., 2013, Twenge et al., 2010, Alhmound and Rjoub 2019).

Businesses are increasingly interested in understanding the impact of human resources management practices and tools on their employees' attitudes and behaviours (White and Bryson 2013). Several research studies have dealt with the impact of total remuneration on employee behaviour and performance. These have confirmed a positive link between human resources management systems, employee performance and improved business 
performance (Purcell et al., 2009). The impact of total remuneration on positive attitudes and behaviour of employees, on job satisfaction, emotional commitment and innovative behaviour of employees was also confirmed by Peluso (2017). Employees that are satisfied with their work are more likely to be stable, productive and businessoriented. Several authors have examined the relationship between total remuneration, happiness at work, and employee engagement (Hofman 2014, Saks 2006). The results of the studies suggest that total remuneration affects employee happiness through their engagement at work. Thus, engagement acts as a mediational factor. Ryan and Deci (2000) argue that total remuneration of employees is related to a positive working approach through internal drive, i.e. employee engagement. This promotes a sense of achievement, generates satisfaction and a positive sense of work. An employee experiences happiness when goals are achieved, and his or her needs are met. According to Baker et al. (2014), if employees receive remuneration in the form of autonomy, recognition, training and development opportunities, they will make further efforts to achieve the goals and accomplish the assigned tasks. This kind of remuneration creates enthusiasm for learning new skills, increases employee activity and interest in meeting goals, expanding the range of opportunities and increasing employees' sense of success. Thus, total remuneration does not directly affect the happiness of employees, but indirectly through increased work commitment (Gulyani end Sharma 2018).

In conclusion, total remuneration in employee motivation can serve as a source of competitive advantage for businesses, aligning employee performance with business goals (Peluso 2017), since engaging and combining different forms of motivation serves as a source of overlapping and mutually reinforcing influence on the performance of employees (Innocenti et al., 2011).

\section{Materials and methods}

The methodological framework of our research is Herzberg's two-factor motivation theory. We have chosen this theory to link the elements of motivation and job satisfaction. It is a simple and transparent tool that allows to explore motivation and job satisfaction as two aspects of human resources management. Motivation and job satisfaction are linked through a pair of factors. On the one hand, they refer to dissatisfactors, or hygienic or frustrating factors that are focused on job satisfaction. These create suitable working conditions and are the external factors of motivation. On the other hand, they pertain to motivators or motivational factors that are the internal factors of motivation. These are directly related to the content and purpose of the work and are a prerequisite for motivation for higher work performance, and their effect on motivation is longterm. Employee satisfaction is influenced by hygienic factors. If these are provided at an insufficient level, they are the source of employee dissatisfaction and frustration. Conversely, if they are set up appropriately, they have the ability to influence employee satisfaction but do not have a direct impact on employee motivation. However, they are equally important to the company because long-term dissatisfaction is a barrier to the employee's motivation to work. 
Due to the specifics of the agribusiness labour market, we have adjusted the factors presented in Herzberg's theory to reflect the specific aspects of this environment. We have chosen the following factors: relations with superiors, relationships with co-workers, status, occupational prestige, organisation image, organisation management (employee awareness), job security, income, employee benefits, working conditions (including the possibility of using modern technical and technological equipment), company culture, career advancement, recognition of personal outcome of work, work itself in terms of its content, possibility of education, responsibility. According to Herzberg, the first 10 factors are hygienic factors, whereas the other factors are motivators.

The survey focused on the analysis of motivation factors of employees in agribusiness companies in terms of job satisfaction and stabilisation in Slovakia. It aimed to find answers to the following research questions:

1. What are the main motivating factors for agribusiness workers?

2. Are there differences between employee expectations and their saturation by management in agribusiness companies?

The following procedure has been chosen:

- identifying individual preferences for motivation factors in the sample of employees,

- finding satisfaction and saturation of motivation factors in the surveyed agribusiness companies,

- analysis of the differences between employees' personal preferences and their subjectively perceived satisfaction within human resources policies in agribusiness companies,

- synthesis of knowledge about motivation factors and job satisfaction of agribusiness employees.

The data needed to answer the set research questions were obtained using a structured questionnaire, which we distributed to agribusiness employees after obtaining consent from their management. We addressed a total of 50 businesses of different legal forms within the agribusiness sector. We chose these agribusiness companies with the intention to homogenise the sample in terms of production areas which were significant in agribusiness operations. The survey was conducted in western Slovakia, where the most productive agricultural areas were located. 35 companies (15 agricultural cooperatives and 20 limited liabilities) were willing to participate in our survey and complete 450 questionnaires. We designed the questionnaire as simply as possible to avoid burdening the respondents and motivating them to cooperate. The research tool consisted of two main parts. The first part focused on the identification data of respondents, i.e. their sex, age, highest-level of education, length of practice. The second part dealt with the motivation aspects of the working activity. Employees were asked to express their subjective perception of the significance of individual motivation factors (A) and how satisfied they felt by the management of the business (B). In order to ensure the 
clarity and simplicity of the questionnaire, but also in order to obtain a rich spectrum of information, the identified motivation factors were classified and then submitted to the employees. Their task was to rank the factors according to individual significance (from 1 to 15). Value 1 was the most significant factor for the respondent, while value 15 was assigned to the factor that the employee ascribed as the least significant. A similar procedure was then used to determine the actual saturation degree of the factors. Respondents set the order according to their level of satisfaction. The choice of the identical way of measuring the significance of both aspects examined (significance and saturation) allowed for the comparison of findings and the subsequent determination of the deviations.

To identify the factors that showed the most significant deviations, we tested independent variables using test statistic methods. We used an independent t-test for each motivation factor and compared the average ranking differences. We were working on a significance level of $5 \%$.

\section{Results and Discussions}

The results have been arranged in two figures according to the average ranking within the chosen motivation factors. Figure 1 provides an insight into the significance of motivation factors by agribusiness employees. It is clear that the income factor came first in the average ranking of 1.3. Almost all respondents rated this as significantly motivating. Based on Herzberg's theory, however, this is a hygienic factor. When appropriately secured, it is hardly perceived by employees, on the other hand, if it is missing, there is considerable dissatisfaction. According to Herzberg, financial evaluation does not directly affect employee motivation. Employees' responsibility (average 2.9) and the content of the work performed (average 4.1) ranked second and third. These are motivators with a direct impact on employee motivation and performance. Furthermore, they consider working conditions, recognition of work results as well as relationships with colleagues as significant. They attach less significance to corporate culture, career advancement, employee benefits, job security, company management awareness, as well as relationships with superiors. The last rungs of their interest included educational opportunities, status, prestige of the profession and the policy of the organisation, which are not perceived by them as significant motivating factors. Knowing the preferences and perceptions of individual factors is a prerequisite for informed decision-making and the findings can therefore be an important incentive for agribusiness management.

Figure 2 provides an overview of the current rate of saturation of the motivation factors in agribusiness companies. The results show how employees' expectations are achieved in terms of motivation. Employees ranked the individual factors 1 to 15 , where the value of 1 is obtained by the factor which fulfils employee satisfaction, and the value of 15 is a factor that is perceived by the employees as very poorly satisfied. We can talk about subjectively perceived saturation of motivation factors. Individual values were then averaged. It is clear from the figure that the relationship with co-workers is 
at the first place in terms of the degree of saturation of motivation factors, the average value of which is 2.2. Job security is immediately behind it, with an average of 2.9, and it is followed by the organisation's policy (4.8) and management awareness (5.9). Knowledge about these factors is important, and as they are hygienic factors, they help to eliminate work dissatisfaction, but they do not stimulate performance motivation. Relationships with superiors and corporate culture are also positively assessed by employees. Conversely, factors that most closely meet employees' expectations are income (13.9), employee benefits (13.2), responsibility (11.8) and working conditions (11.7).

Figure 1. Employee opinions on their personal motivation factors

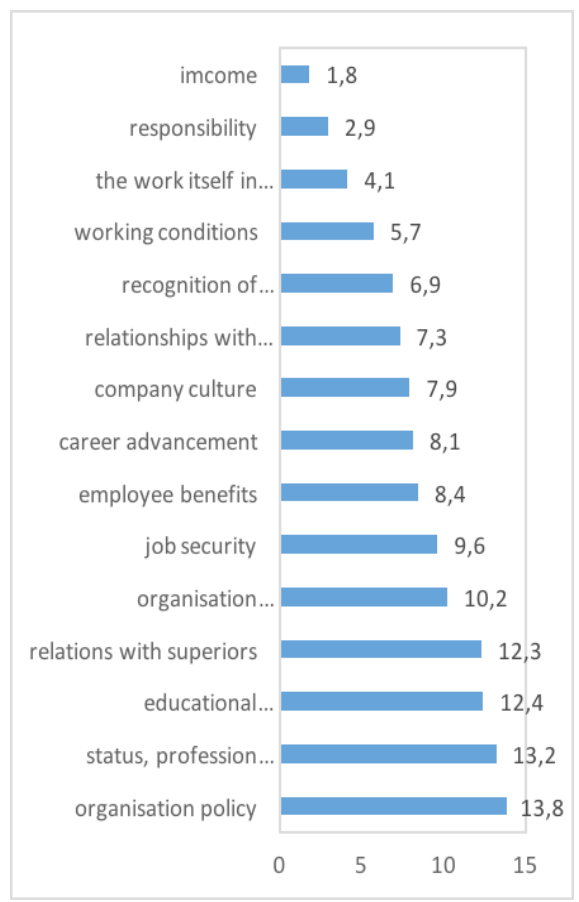

Figure 2. Employees' expectations of motivation by employers

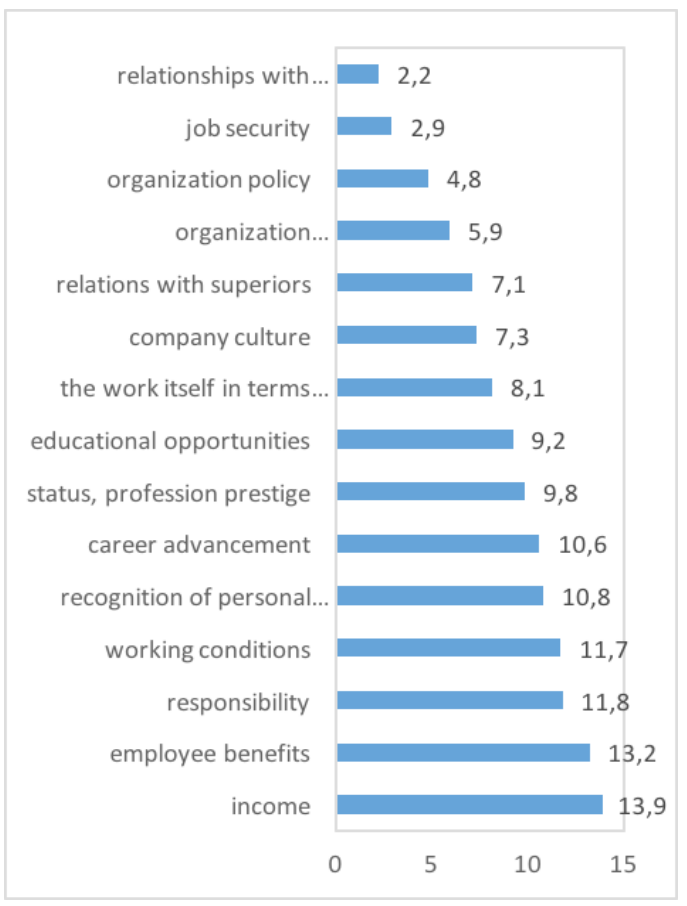

Source: Authors' own processing

We then compared the obtained results, using the deviations between employees' expectations and their satisfaction by employers. It is obvious that the optimal, or a desirable situation arises when a factor rated as significant by the employee (has the lowest value assigned) shows a high degree of saturation by the employer (also has the lowest value assigned). A critical situation arises when a high degree of significance by the employee is linked to poor satisfaction by the employer. High deviations indicate a significant divergence between the personal ranking of employees' priorities and their satisfaction by the employer. They can cause work dissatisfaction and become a factor causing frustration. 
Figure 3. Deviations between employee expectations and their satisfaction by the employer

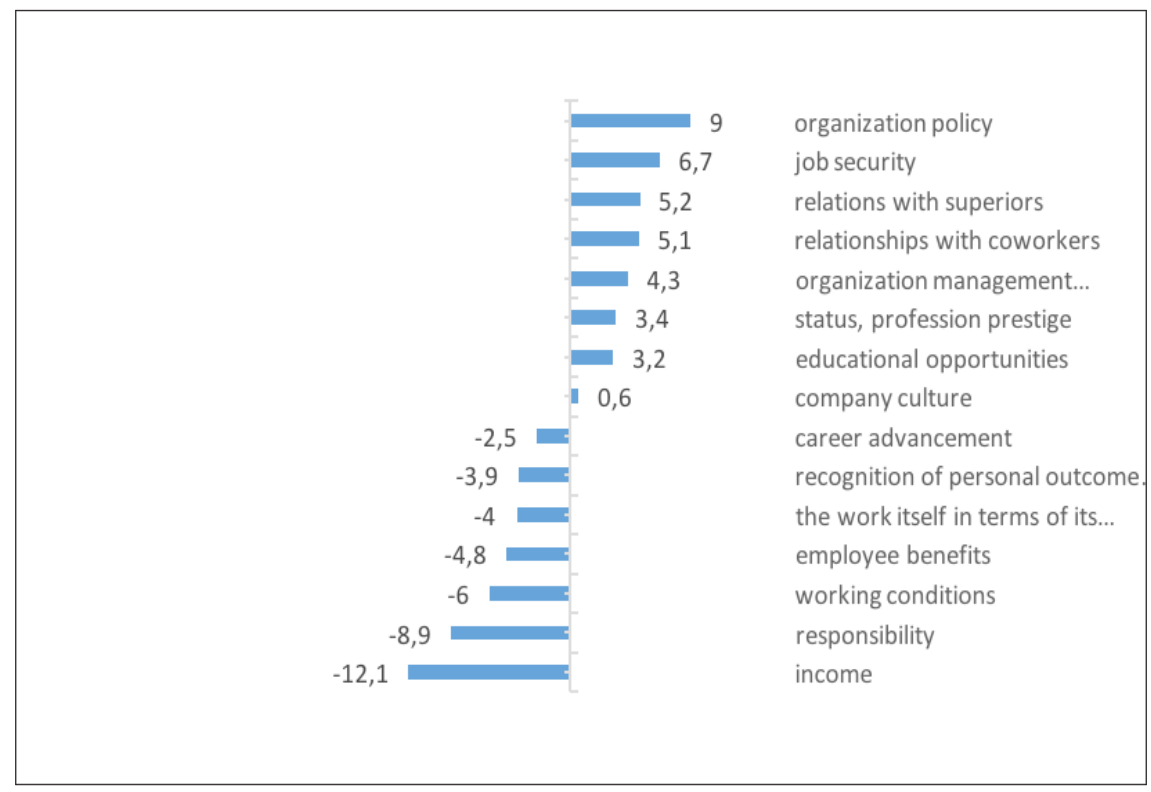

Source: Authors' own processing

The greatest negative deviation is shown by the income factor $(-12.1)$. Such tension can be a source of strong employee dissatisfaction. Income comes first in importance among employees' motivation factors. According to Herzberg's motivation theory, it is a motivator that causes a high level of job dissatisfaction. Significant negative deviation has also been reflected in the responsibility factor (-8.9). Employees perceive this factor as strongly motivational (comes second in importance), but it is currently neither satisfied nor fulfilled. Responsibility as a motivator greatly influences job satisfaction and motivation for performance. Negative deviations have been identified in working conditions and employee benefits, which are again dissatisfactors with the potential to cause significant work dissatisfaction, but also in motivation factors such as the content of work, the recognition of work outcomes and the possibility of progress, affecting not only work satisfaction but also motivation. However, these are currently not being fulfilled in agribusiness companies. Positive deviations suggesting management's commitment to meeting the motivational expectations of its employees have been identified in relation to corporate relationships, management and its efforts to share information, and in relation to corporate policy and corporate culture.

Differences in motivation factors according to individual identification characteristics were examined at the highest negative deviations. A statistically significant difference was found at the age and education of respondents. We used an independent t-test for each motivation factor, comparing the average ranking differences for the two groups of employees, younger (up to 40 years of age) and older (over 40 years of age), as well as for employees with and without higher education. The results are shown in the following tables. 
Table 1. Difference between expectations and satisfaction within motivational aspects by age

\begin{tabular}{|c|c|c|c|c|c|c|}
\hline & $\begin{array}{l}\text { All } \\
\text { respondents }\end{array}$ & By age & & $\begin{array}{l}\text { T-statistic } \\
\text { (absolute } \\
\text { value) }\end{array}$ & $\begin{array}{l}\text { degrees } \\
\text { of } \\
\text { freedom }\end{array}$ & $\begin{array}{l}\text { P-value } \\
\text { (bilateral) }\end{array}$ \\
\hline Motivation & & younger & older & & & \\
\hline Job security & $-6,9$ & $-6,0$ & $-7,8$ & 0,477 & 448 & 0,63 \\
\hline $\begin{array}{l}\text { Relationships with co- } \\
\text { workers }\end{array}$ & 0,6 & 0,8 & 0,4 & 0,970 & 448 & 0,33 \\
\hline Income & $-8,3$ & $-9,5$ & $-5,4$ & 2,027 & 448 & 0,04 \\
\hline Contents of work & 1,2 & 1,8 & 0,6 & 0,510 & 448 & 0,61 \\
\hline Responsibility & $-4,6$ & $-7,3$ & $-2,1$ & 2,192 & 448 & 0,03 \\
\hline Recognition of work & $-3,2$ & $-6,1$ & $-1,9$ & 2,247 & 448 & 0,03 \\
\hline Company culture & 0,6 & 0,6 & 0,6 & 1,197 & 448 & 0,23 \\
\hline Career progression & $-2,1$ & $-1,6$ & $-2,6$ & 1,092 & 448 & 0,28 \\
\hline Working conditions & $-3,3$ & $-6,4$ & $-1,8$ & 2,569 & 448 & 0,01 \\
\hline $\begin{array}{l}\text { Relationship with the } \\
\text { supervisor }\end{array}$ & 3,7 & 3,2 & 4,2 & 0,202 & 448 & 0,84 \\
\hline Employee benefits & $-2,9$ & $-3,8$ & $-2,0$ & 0,040 & 448 & 0,97 \\
\hline Profession prestige & 4,3 & 5,3 & 3,3 & 0,314 & 448 & 0,75 \\
\hline Education & 5,2 & 4,8 & 5,6 & 0,416 & 448 & 0,68 \\
\hline Management & 1,3 & 0,5 & 2,1 & 0,747 & 448 & 0,46 \\
\hline Image & 8,4 & 8,2 & 8,6 & 1,006 & 448 & 0,31 \\
\hline
\end{tabular}

Source: Authors' own processing

Table 2. Difference between expectations and satisfaction in terms of motivation according to education

\begin{tabular}{|l|l|l|l|l|l|l|}
\hline & Respondents & \multicolumn{2}{|l|}{ By education } & T-statistic & df & P-value \\
\hline Motivation & & $\begin{array}{l}\text { Higher } \\
\text { education }\end{array}$ & $\begin{array}{l}\text { Without } \\
\text { higher } \\
\text { education }\end{array}$ & & & \\
\hline Job security & $-6,9$ & $-8,5$ & $-5,4$ & 0,366 & 448 & 0,71 \\
\hline $\begin{array}{l}\text { Relationships with co- } \\
\text { workers }\end{array}$ & 0,6 & $-1,3$ & 2,5 & 1,026 & 448 & 0,31 \\
\hline Income & $-8,3$ & $-8,5$ & $-8,1$ & 0,151 & 448 & 0,88 \\
\hline Content of the work & 1,2 & $-1,9$ & 4,3 & 2,447 & 448 & 0,01 \\
\hline Responsibility & $-4,6$ & $-7,2$ & $-2,1$ & 2,647 & 448 & 0,01 \\
\hline Recognition of work & $-3,2$ & $-7,8$ & 1,4 & 2,180 & 448 & 0,03 \\
\hline Company culture & 0,6 & 0,9 & 0,3 & 0,325 & 448 & 0,75 \\
\hline
\end{tabular}




\begin{tabular}{|l|l|l|l|l|l|l|}
\hline & Respondents & \multicolumn{2}{l|}{ By education } & T-statistic & df & P-value \\
\hline Career progression & $-2,1$ & $-6,4$ & 2,2 & 2,585 & 448 & 0,01 \\
\hline Working conditions & $-3,3$ & $-2,2$ & $-4,4$ & 0,742 & 448 & 0,46 \\
\hline $\begin{array}{l}\text { Relationship with the } \\
\text { supervisor }\end{array}$ & 3,7 & 3,0 & 4,4 & 0,834 & 448 & 0,40 \\
\hline Employee benefits & $-2,9$ & $-2,9$ & $-2,9$ & 1,310 & 448 & 0,19 \\
\hline Profession prestige & 4,3 & 3,8 & 4,8 & 0,360 & 448 & 0,72 \\
\hline Education & 5,2 & 5,5 & 4,9 & 0,762 & 448 & 0,45 \\
\hline Management & 1,3 & 1,1 & 1,5 & 0,130 & 448 & 0,90 \\
\hline Image & 8,4 & 9,2 & 7,6 & 0,408 & 448 & 0,68 \\
\hline
\end{tabular}

Source: Authors' own processing

The most significant differences in terms of the age of employees were found in the motivation factors such as income, responsibilities, working conditions and recognition of personal results of work, and these differences were at a significance level of $5 \%$. This means that there were higher negative deviations in these factors in the case of younger employees and therefore there is a significant difference between the expectations of younger employees in these factors and their fulfilment by the employer. We achieved the same significant result in terms of employee education. Employees with higher education have shown higher negative deviations for the factors of responsibility, content of work, recognition of personal outcome and career advancement, where there is a significant difference between the expectations of higher education employees in these factors and their fulfilment by the employer.

\section{Conclusions}

The results of the survey have shown that income is clearly the most significant motivation factor for agribusiness employees. These findings are consistent with the conclusions of Hitka et al. (2019) who examined and analysed the motivation of employees in terms of gender, work category and age in companies in Slovakia. The results also show that the financial category, including basic salary, other financial remuneration, including fair remuneration, is the main motivation for all work categories in all age groups. At the same time, income is the factor in which employees' expectations diverge most from reality. Negative deviation between the rate of significance and saturation of this factor is the highest among all surveyed. This is more noticeable in the category of employees under 40 years of age. These findings are important because they verify the failure to meet employees' expectations, what requires an urgent solution in the agribusiness industry to stabilise the human factor and build competitiveness on the labour market. In addition, the findings of Kolman et al. (2006) highlight that if people do not trust that they will be fairly rewarded for their work, this in turn reduces their responsibility and interest in the work itself. In the evaluation of the significance of 
individual motivational factors, motivators such as employee responsibility, work itself and recognition of the results were highly ranked in agribusiness companies. These factors, having the ability to stimulate performance growth, are assessed by employees as important. Management should therefore pay due attention to them. Responsibility is, however, the category where saturation falls short of significance, which is most felt in the category of younger and educated employees. Likewise, the factors of work content and the recognition of outcome, which are perceived as important by employees, show high negative deviations. Positive deviations between the significance and the degree of saturation of the motivation factor reveal the efforts to motivate employees with tools that they do not perceive as very important. This is the case of job security, organisational policy and employee information by management. The high level of their saturation is a manifestation of a correct and qualified approach of agribusiness management to its employees, which can be evaluated very positively. It also creates conditions for long-term employee satisfaction, but significant disproportions in meeting income expectations are a barrier to achieving this. It can be concluded that the expectations of employees and the currently applied motivational tools by management are in many respects contradictory.

\section{Acknowledgements}

This research was supported by the Vega Project 1/0017/20 Changes in the implementation of management functions in the context of the fourth industrial revolution and the adaptation processes of businesses in Slovakia.

\section{Conflict of interests}

The authors declare no conflict of interest.

\section{References}

1. Alhmoud A., Rjoub, H. (2019). Total Rewards and Employee Retention in a Middle Eastern Context. SAGE open, 9(2), 1-13.

2. Armstrong, M., \& Murlis, H. (2007). Reward Management: A Handbook of Remuneration Strategy and Practice. Philadephia, 722.

3. Blaas, G., Bielek, P., \& Božík, M. (2010). Land and agriculture. Reflections on the future. Bratislava, 35 .

4. Bakker, A.B., Demerouti, E., \& Sanz-Vergel, A.I. (2014). Burnout and work engagement: the JD-R approach. Annual Review Organizational Psychology of Organization Behaviour, 1, 389-411.

5. Gulyani, G., \& Sharma, T. (2018). Total rewards components and work happiness in new ventures: The mediating role of work engagement. Evidence-based HRM, 3, 255-271.

6. Hitka, M. (2019). Mathematical model of motivation. Zvolen,134. 
7. Chen, H., \& Hsieh, Y. (2006). Key trends of the total reward system in the $21 \mathrm{st}$ century. Compensation Benefits Review, 6, 64-70.

8. Innocenti, L., Pilati, M., \& Peluso, A.M. (2011). Trust as moderator in the relationship between HRM practices and employee attitudes. Human Resource Management Journal, 3, 303-317.

9. Kolman, P., Michálek, H., Chamutová, H., Chamutová, K., \& Müllerová L. (2007). Work motivation and the municipality size. Agricultural Economics Czech, 53, 30-35.

10. Manas, T., \& Graham, M.D. (2002). Creating a Total Rewards Strategy: A Toolkit for Designing Business-Based Plans. New York, 352.

11. Morgan, J.C., Dill, J., \& Kalleberg, A.L. (2013). The quality of healthcare jobs: Can intrinsic rewards compensate for low extrinsic rewards? Work, Employment and Society 27, $802-822$.

12. Peluso, A.M. (2017). Pay is no everything. Evidence-based HRM, 5(3), 311-327.

13. Purcell, J., Kine, N., Swart, J., Rayton, B., Hutchinson, S. (2009). People Management and Performance, London, 228s.

14. Ryan, R.M., \& Deci, E.L. (2000). Self-determination theory and the facilitation of intrinsic motivation, social development, and well-being. American Psychologist 1, 68-78.

15. Saks, A.M. (2006). Antecedents and consequences of employee engagement. Journal of Managerial Psychology 7, 600-619.

16. Twenge, J.M. (2010). A review of the empirical evidence on generational differences in work attitudes. Journal of Business and Psychology, 25, 201-210.

17. White, M., \& Bryson, A. (2013). Positive employee attitudes: how much human resource management do you need? Human Relations, 66(3), 385-406.

18. Williamson, I.O., Burnett, M.F., \& Bartol, K.M. (2009). The interactive effect of collectivism and organizational rewards on affective organizational commitment. Cross Cultural Management: An International Journal, 16, 28-43. 